\title{
Helicobacter pylori in patients with gastritis in West Cameroon: prevalence and risk factors for infection
}

\author{
Nathan E. Agbor ${ }^{1}$, Seraphine N. Esemu ${ }^{1,2^{*}}$, Lucy M. Ndip ${ }^{1,2}$, Nicoline F. Tanih ${ }^{3}$, Stella I. Smith ${ }^{4}$ \\ and Roland N. Ndip ${ }^{1,2}$
}

\begin{abstract}
Objectives: Helicobacter pylori is a pathogenic bacterium that parasitizes the gastric mucous layer and the epithelial lining of the stomach causing duodenal ulcers, gastric ulcers and cardiovascular disease amongst others. This study aimed at establishing the epidemiologic profile of H. pylori infection in gastritis patients presenting at the Melong District Hospital.

Results: Blood, stool and epidemiological data collected from 500 patients were analyzed for the presence of $H$. pylori antibody in serum, antigen in stool and elucidation of risk factors captured in questionnaires. Of 500 blood samples, 217 (43.4\%) were seropositive with male and female seroprevalences of 45.5\% (61/134) and 42.6\% (156/366) respectively. Similarly, 47.4\% (237/500) samples tested positive for stool antigen with prevalences of $47.0 \%(63 / 134)$ for males and $47.5 \%$ (174/366) for females. The antigen prevalence was higher $(53.2 \% ; 118 / 222)$ in older patients (>50 years) than in younger patients (42.8\%; 119/278; $\mathrm{P}=0.021)$. The antigen test had a higher (47.4\%) prevalence than the antibody test (43.4\%). Educational level, source of income, source of drinking water, age of patients, and alcohol consumption had positive associations with H. pylori infection. These results have clinical and epidemiological significance and call for intervention to mitigate the situation.
\end{abstract}

Keywords: Gastritis, Helicobacter pylori, Prevalence, Risk factors, Cameroon

\section{Introduction}

Helicobacter pylori, a bacterium that parasitizes the gastric mucous layer and the epithelial lining of the stomach, is a Class I carcinogen and the predominant bacterium that colonizes the stomach mostly during childhood $[1,2]$. This bacterium infects over $50 \%$ of the world's population and is a frequent cause of chronic bacterial infections [3]. Approximately $10 \%$ of infected individuals develop overt clinical disease while $90 \%$ remain subclinical and the infection can persist throughout life if untreated [4]. So far, H. pylori has 20 recognized strains [5] that have been implicated in many diseases including duodenal ulcers, gastric ulcers, adenocarcinoma of

\footnotetext{
*Correspondence: esemu2003@yahoo.co.uk

${ }^{1}$ Department of Microbiology and Parasitology, University of Buea, P. O. Box 63, Buea, Cameroon

Full list of author information is available at the end of the article
}

the distal stomach, mucosa-associated lymphoid tissue (MALT) lymphoma, diabetes mellitus, cardiovascular disease and autoimmune disease $[1,5]$. Treatment failure of $H$. pylori infection has been linked to bacterial resistance and poor patient compliance [6, 7].

The routes of transmission of $H$. pylori have not been clearly identified. Houseflies have been shown to have the potential to transmit the organism mechanically implying poor sanitation is a risk factor for its spread [8]. Transmission from person-to-person and through tubes or endoscopes have been reported. Use of water contaminated with faeces may predispose people to $H$. pylori infection $[8,9]$ and if the water source is a municipal water supply, this may potentiate its spread. Factors that have been associated with the acquisition of $H$. pylori infection include high density crowding, poor sanitary 
practices, family income, educational level, age, occupation, religion and poor water supply $[4,10,11]$.

There is great geographical variation in the prevalence of $H$. pylori with higher prevalence in developing than in developed countries [1, 12]. Knowledge of $H$. pylori status is very important in patient management. Diagnosis relies on invasive and non-invasive techniques and noninvasive techniques (such as stool test and serology) are preferable in epidemiological studies [13]. The stool test demonstrates the presence of antigens while serology detects antibodies to $H$. pylori. However, serologic tests are limited by false positivity because of cross-reactions [13]. Previous studies have confirmed the superiority of the stool antigen test over serology in terms of true outcomes and cost [14].

There is a paucity of information on the prevalence of H. pylori and associated risk factors in Cameroon. Previous studies in Cameroon reported H. pylori prevalence of $72 \%$ (67/93) from biopsies samples with evidence of gastritis [15] and 92.2\% from gastric biopsies of patients with gastroduodenal pathologies [16]. It was therefore important to conduct this hospital-based cross-sectional study to generate recent spatiotemporal data on $H$. pylori prevalence and risk factors for infection to inform prevention and control measures.

\section{Main text}

\section{Study site and participants}

The study was conducted at the Melong District Hospital which serves as a referral centre for health facilities within the Melong Health District. Melong is located at $5^{\circ} 07^{\prime} 18^{\prime \prime} \mathrm{N}$ and $9^{\circ} 57^{\prime} 41^{\prime \prime} \mathrm{E}$ in a rainforest zone and $792 \mathrm{~m}$ above sea level. The inhabitants are predominantly traders, artisans and farmers and their socioeconomic status predisposes them to infections associated with personal and environmental hygiene. Five hundred patients of both sexes, who consulted at the hospital with signs and symptoms of chronic gastritis, were enrolled in this study from August 2013 to September 2015.

\section{Ethical considerations}

Ethical clearance was obtained from the Institutional Review Board of the Faculty of Health Sciences, University of Buea (Reference No. 2015/347/UB/FHS/IRB of 1 July 2015). Administrative authorizations were obtained from the Regional Delegation of Public Health for the Littoral Region and the Director of the Melong District Hospital. Samples were collected only from patients who gave their consent to participate in the study.

\section{Sample collection}

Blood and stool were collected for serology and antigen tests respectively. Epidemiological data were also collected for risk factors assessment. Two milliliters of blood were collected aseptically from each study participant by venipuncture and transferred to a sterile vacutainer tube without anticoagulant. The blood was allowed to clot by leaving it undisturbed at room temperature for $45 \mathrm{~min}$, centrifuged at $2000 \times \mathrm{g}$ for $10 \mathrm{~min}$ and the serum harvested. The stool sample (1-2 mL or 1-2 g) was collected with the use of a catching device and put in a sterile screw-capped bottle. All samples were stored at $+4{ }^{\circ} \mathrm{C}$ until processed.

Epidemiological data captured on questionnaires included socio-demographic data (sex, age, marital status, educational level), socioeconomic factors (household population, source of income, source of drinking water and toileting system) and health determining behaviours (cigarette and alcohol consumption).

\section{Sample processing}

Serum analysis was done using a One-step H. pylori antibody test device (DiaSpot, Indonesia) according to the manufacturer's instructions. Briefly, three drops of the serum sample were applied directly into the sample well in the test device and results read after $10 \mathrm{~min}$. The appearance of one coloured line on the control region indicated a negative result while the appearance of two coloured lines on the test region and control regions indicated positive result.

Stool analysis was done using a One-step H. pylori antigen test device (ABON Bioparm Hangzhou, China). The test was performed according to the manufacturer's instructions without any modifications. Briefly, $50 \mathrm{mg}$ (from formed stool) or two drops of liquid stool were transferred to a specimen collection tube containing extraction buffer. The tube was agitated vigorously by hand-shaking and left undisturbed for $2 \mathrm{~min}$. Two drops of the extracted specimen were transferred to the specimen well on the test device and results read after $10 \mathrm{~min}$.

\section{Statistical analysis}

The $\chi^{2}$ test was used to analyze the data. $P<0.05$ was considered statistically significant. All calculations were carried out with Epi Info version 3.5.4 (CDC, Atlanta, USA).

\section{Results}

\section{Prevalence of $H$. pylori infection}

Of the 500 stool samples analysed, $H$. pylori antigen was detected in 237 (47.4\%). The prevalence of $H$. pylori antigen in females was $47.5 \%(174 / 366)$ and $47.0 \%(63 / 134)$ in males. However, this difference was not statistically significant. The distribution of the H. pylori stool antigen positive samples with respect to other patient characteristics are presented in Table 1. Overall, 217 (43.4\%) of the 500 serum samples analysed had antibodies against 
Table 1 Characteristics of study participants and Helicobacter pylori positivity

\begin{tabular}{|c|c|c|c|c|}
\hline \multirow[t]{2}{*}{ Variables } & \multirow[t]{2}{*}{ Total participants } & \multicolumn{2}{|c|}{ Number positive for H. pylori } & \multirow[t]{2}{*}{ P-value } \\
\hline & & Stool antigen (\%) & Serology (\%) & \\
\hline \multicolumn{5}{|l|}{ Sex } \\
\hline Male & 134 & $63(47.0)$ & $61(45.5)$ & \multirow[t]{2}{*}{0.917} \\
\hline Female & 366 & $174(47.5)$ & $156(42.6)$ & \\
\hline \multicolumn{5}{|l|}{ Age group (years) } \\
\hline$<50$ & 278 & $119(42.8)$ & $123(44.2)$ & \multirow[t]{2}{*}{$0.021^{* *}$} \\
\hline$>50$ & 222 & $118(53.2)$ & $94(42.3)$ & \\
\hline \multicolumn{5}{|l|}{ Education } \\
\hline None & 25 & $20(80.0)$ & $18(72.0)$ & \multirow[t]{4}{*}{$0.000^{* *}$} \\
\hline Primary & 235 & $125(53.2)$ & $111(47.2)$ & \\
\hline Secondary & 207 & $92(44.4)$ & $88(42.5)$ & \\
\hline Tertiary & 33 & $0(0)$ & $0(0)$ & \\
\hline \multicolumn{5}{|l|}{ Source of income } \\
\hline Agriculture/trading & 360 & $177(49.2)$ & $160(44.4)$ & \multirow[t]{4}{*}{$0.000^{* *}$} \\
\hline Service & 52 & $22(42.3)$ & $21(40.4)$ & \\
\hline Housewife/retired & 68 & $20(29.4)$ & $20(29.4)$ & \\
\hline Others & 20 & $18(90.0)$ & $16(80.0)$ & \\
\hline \multicolumn{5}{|c|}{ Source of drinking water } \\
\hline Tapwater & 240 & $105(43.8)$ & $98(40.8)$ & \multirow[t]{4}{*}{$0.006^{* *}$} \\
\hline Spring & 250 & $125(50.0)$ & $113(45.2)$ & \\
\hline Bottled & 7 & $7(100)$ & $6(85.7)$ & \\
\hline Others & 3 & $0(0)$ & $0(0)$ & \\
\hline \multicolumn{5}{|c|}{ Duration of gastritis symptoms (years) } \\
\hline$<1$ & 197 & 74 (37.6) & $70(35.5)$ & \multirow[t]{4}{*}{$0.003^{* *}$} \\
\hline $1-3$ & 110 & $60(54.5)$ & $57(51.8)$ & \\
\hline $3-4$ & 47 & $22(46.8)$ & $15(31.9)$ & \\
\hline$>4$ & 146 & $81(55.5)$ & $75(51.4)$ & \\
\hline \multicolumn{5}{|l|}{ Household population } \\
\hline $1-3$ & 142 & $69(48.6)$ & $61(43.0)$ & \multirow[t]{3}{*}{0.055} \\
\hline $4-5$ & 220 & $108(49.1)$ & $97(44.1)$ & \\
\hline$>5$ & 138 & $60(43.5)$ & $59(42.8)$ & \\
\hline \multicolumn{5}{|l|}{ Toileting system } \\
\hline Leads to drainage & 122 & $64(52.5)$ & $60(49.2)$ & \multirow[t]{3}{*}{$0.044^{* *}$} \\
\hline Closed pit & 365 & $167(45.8)$ & $153(41.9)$ & \\
\hline Others & 13 & $6(46.2)$ & $4(30.8)$ & \\
\hline \multicolumn{5}{|l|}{ Alcohol consumption } \\
\hline Yes & 332 & $169(50.9)$ & $156(47.0)$ & \multirow[t]{2}{*}{$0.027^{* *}$} \\
\hline No & 168 & $68(40.5)$ & $61(36.3)$ & \\
\hline \multicolumn{5}{|c|}{ Tobacco consumption (smoker) } \\
\hline Yes & 132 & $59(44.7)$ & $57(43.2)$ & \multirow[t]{2}{*}{0.468} \\
\hline No & 368 & $178(48.4)$ & $160(43.5)$ & \\
\hline Smokers $(n=132)$ & & & & \\
\hline Regular smokers & 78 & $25(32.1)$ & $22(28.2)$ & $0.000^{* *}$ \\
\hline Occasional smokers & 54 & $34(63.0)$ & $29(53.7)$ & \\
\hline
\end{tabular}

Stool antigen test considered as gold standard

** Significant differences 
H. pylori. Similarly, the seroprevalence in females (42.6\%, $156 / 366)$ was almost the same as that in males $(45.5 \%$, $61 / 134)$. Most $(56.7 \%, 123 / 217)$ of the seropositive samples were from patients less than 50 years old (Table 1).

The antigen test detected a higher number (237) of positive samples and was used to calculate the sensitivity and specificity of the antibody test which were 89.9 and 98.5\% respectively. The antibody test failed to detect 24 samples which were positive for $H$. pylori using antigen test. Four samples were positive by the antibody test only. Test results were concordant for 213 samples. A total of 24 samples produced discordant results (Table 2).

Although the antigen test consistently detected a higher number of positives in all sub-populations of the patients analysed (Table 1) The difference in the detection rates between the two tests was not significant $(\mathrm{P}=0.204)($ Table 2$)$.

\section{Risk factors for $\boldsymbol{H}$. pylori infection}

This study revealed several risk factors for $H$. pylori infection. Patient variables, including socioeconomic characteristics, were examined for associations with $H$. pylori infection (Table 1). Education, age, source of income, source of drinking water, alcohol consumption and toileting system had statistically significant $(\mathrm{P}<0.05)$ associations with $H$. pylori infection. The prevalence of the infection decreased with increasing level of education with highest $(20 / 25,80 \%)$ prevalence among those with no level of education and lowest (0\%) prevalence among those who had tertiary level of education. Tobacco consumption, household population, and sex showed no association $(\mathrm{P}>0.05)$ with $H$. pylori infection.

\section{Discussion}

This study sought to establish the epidemiological profile of $H$. pylori in patients presenting at the Melong District Hospital with signs and symptoms of gastritis. The large representation $(73.2 \%, 366 / 500)$ of females in the study population revealed that more females consulted at the hospital with symptoms of chronic gastritis than males $(26.8 \%, 134 / 500)$. This large representation of females could be due to the global demographic profile which shows that the women population exceeds that of the

Table 2 Outcome of the detection of $\boldsymbol{H}$. pylori infection in $\mathbf{5 0 0}$ patients by both tests

\begin{tabular}{llrrr}
\hline & \multicolumn{2}{c}{ Stool antigen test } & Total \\
\cline { 2 - 4 } & \multicolumn{2}{c}{+} & \multicolumn{1}{c}{} \\
\hline Serology & + & 213 & 4 & 217 \\
& - & 24 & 259 & 283 \\
Total & & 237 & 263 & 500 \\
\hline
\end{tabular}

men. However, there was no statistically significant difference in the antigen prevalence in males and females corroborating earlier results [17].

The prevalence of $H$. pylori has a wide geographical variation and over the years, decreasing prevalence has been reported in several areas of the globe $[1,18]$. The overall prevalence of $H$. pylori infection in this study was $43.4 \%(217 / 500)$ for serology and $47.4 \%$ for stool antigen test. A previous study reported a seroprevalence of $36.7 \%$ in rural Vietnam [19]. Generally, the prevalence of H. pylori is expected to decrease with improvement in the socioeconomic and hygiene status of the population. An earlier study reported an $H$. pylori seroprevalence of 66.9\% in 1998 which dropped to $59.6 \%$ in 2005 in South Korea [20]. H. pylori prevalence varies from one place to another based on the socioeconomic and hygienic condition of the environment and in the same environment, the prevalence of the same infection can vary with time [20]. There was no statistically significant difference $(\mathrm{P}=0.917)$ in the seroprevalence results between females $(42.6 \%, 156 / 366)$ and males $(45.5 \%, 61 / 134)$ and similar results have been reported elsewhere [17]. The antigen prevalence $(47.4 \%)$ reported in this study was low compared to that reported earlier $(52.27 \%$; $92 / 176)$ in stool of asymptomatic children in Buea and Limbe health districts of Cameroon [21]. While an earlier study in Cameroon reported a high $H$. pylori prevalence $(92.2 \%$, 71/77) in patients referred for endoscopy [16], a study in the North West Province of Cameroon showed a lower prevalence of $72 \%$ (67/93) [15]. These differences in prevalence may be due to improvement in the socioeconomic and hygiene conditions of the population over time. In a recent study carried out in North Sulawesi and Indonesia, a much lower prevalence of $14.3 \%(36 / 251)$ was reported [18].

Several studies have been published on risk factors for infection, but the findings have been conflicting. Generally, the infection has been shown to be higher among those with low socioeconomic and hygiene state [22]. The antigen prevalence in elderly persons $(\geq 50$ years) was higher $(53.2 \%)$ than in the young $(<50$ years) $(42.8 \%)$ and this difference was statistically significant $(\mathrm{P}<0.05)$. Previous studies also noted that the infected participants were significantly older than those that did not have the infection $[17,23]$. Ageing is associated with a diminished epithelial cell turnover rate and a reduced capacity to repair the gastric mucosa [23] and this has been attributed to decreasing prostaglandin levels in the gastric mucosa making age a major risk factor for $\mathrm{H}$. pylori colonization [24].

Studies on association between $H$. pylori and smoking or alcohol drinking report conflicting results. A study in Brazil reported no statistical significant effect of smoking 
and alcohol consumption on $H$. pylori prevalence [25]. Our study showed that $H$. pylori infection was higher among alcohol consumers (51.1\%) than among those who had never had alcohol consumption as a habit (40.3\%) and this corroborates a previous study [26].

The antigen prevalence was lower among smokers $(44.7 \%, 59 / 132)$ than among non-smokers $(48.4 \%$, $178 / 368)$. Similarly, regular smokers had a lower prevalence of $32.1 \%$ compared to $63.0 \%$ among the occasional smokers. This contradicts a previous study that reported that $H$. pylori infection was more in smokers and exsmokers than in those who had never smoked [27]. An earlier attempt to study these risk factors could not establish any relationship between the infection and smoking [17]. In a recent large scale study, it was reported that smoking was negatively associated with $H$. pylori infection and the risk of the infection was noted to linearly decrease with cigarette consumption per day [28]. Cigarette smoking results in increase in gastric acidity and this may account for the negative association between smoking and H. pylori infection [29].

\section{Conclusion}

This study revealed an $H$. pylori seroprevalence and antigen prevalence of 43.4 and $47.5 \%$ respectively with no statistically significant difference. Among risk factors assessed, educational level, source of income, cigarette smoking and alcohol consumption were statistically associated with $H$. pylori infection.

\section{Limitations}

All individuals sampled were hospital patients with signs and symptoms of chronic gastritis hence the spatiotemporal results from this study cannot be generalized to represent $H$. pylori prevalence and risk factors in the general population in Cameroon. This study needs to be expanded to other areas of the country as well as the inclusion of healthy individuals as a control group.

\section{Abbreviations \\ H. Pylori: Helicobacter pylori; MALT: mucosa-associated lymphoid tissue.}

\section{Authors' contributions}

NEA, SIS and RNN conceived the study; SNE, LMN, NFT and SIS designed the study and assisted in data analysis; NEA and SNE assisted in sample collection and laboratory analysis; SNE and NFT drafted the manuscript; RNN, SIS and LMN reviewed the manuscript. All authors read and approved the final manuscript.

\section{Author details}

${ }^{1}$ Department of Microbiology and Parasitology, University of Buea, P. O. Box 63, Buea, Cameroon. ${ }^{2}$ Laboratory for Emerging Infectious Diseases, University of Buea, Buea, Cameroon. ${ }^{3}$ Medical Research Council Unit, Fajara, Gambia. ${ }^{4}$ Nigerian Institute of Medical Research, Lagos, Nigeria.

\section{Acknowledgements}

None.

\section{Competing interests}

The authors declare that they have no competing interests.

\section{Availability of data and materials}

Additional data generated from this study could be obtained on request from the corresponding author.

\section{Consent for publication}

Not applicable.

\section{Ethics approval and consent to participate}

The study was reviewed and approved by the Institutional Review Board, Faculty of Health Sciences, University of Buea, Cameroon (2015/347/UB/FHS/ IRB). Authorization to carry out this study at the Melong District hospital was obtained from the Regional Delegation of Public Health for the Littoral Region. Written informed consent was obtained from each study participant before samples were taken.

Funding

None.

\section{Publisher's Note}

Springer Nature remains neutral with regard to jurisdictional claims in published maps and institutional affiliations.

Received: 4 May 2018 Accepted: 30 July 2018

Published online: 03 August 2018

\section{References}

1. Yu X, Yang X, Yang T, Dong Q, Wang L, Feng L. Decreasing prevalence of Helicobacter pylori according to birth cohorts in urban China. Turk J Gastroenterol. 2017;28:94-7.

2. Yucel O. Prevention of Helicobacter pylori infection in childhood. World J Gastroenterol. 2014;20:10348-54.

3. Kao C-Y, Sheu B-S, Wu J-J. Helicobacter pylori infection: an overview of bacterial virulence factors and pathogenesis. Review article. Biomed J. 2016:39(1):14-23.

4. Testerman TL, Morris J. Beyond the stomach: an updated view of Helicobacter pylori pathogenesis, diagnosis, and treatment. World I Gastroenterol. 2014;20(36):12781-808.

5. Gunaletchumy SP, Seevasant I, Tan MH, Croft L, Mitchell HM, Goh KL, et al. Helicobacter pylori genetic diversity and gastro-duodenal diseases in Malaysia. Sci Rep. 2014;4:7431

6. Yang J-C, Lu C-W, Lin C-J. Treatment of Helicobacter pylori infection: current status and future concepts. World J Gastroenterol. 2014;20:5283-93.

7. Tanih NF, Okeleye BI, Green E, Mkwetshana N, Clarke AM, Ndip LM, et al. Marked susceptibility of South African Helicobacter pylori strains to ciprofloxacin and amoxicillin: clinical implications. S Afr Med J. 2010;100:49-52.

8. Perry S, de la Luz Sanchez M, Yang S, Haggerty TD, Hurst P, Perez-Perez G, Parsonnet J. Gastroenteritis and transmission of Helicobacter pylori infection in households. Emerg Infect Dis. 2006;12(11):1701-8.

9. Zhu Y, Zhou X, Wu J, Su J, Zhang G. Risk Factors and Prevalence of Helicobacter pylori infection in persistent high incidence area of gastric carcinoma in Yangzhong City. Clinical Study. Gastroenterol Res Pract. 2014:2014:481365.

10. Yakoob J, Fatima SS, Abbas Z, Mustafa SF, Khan HAR, Raghib MF, et al. Distribution of gastric carcinoma in an area with a high prevalence of Helicobacter pylori. Turk J Gastroenterol. 2017;28:98-103.

11. Tanih NF, Okeleye BI, Naidoo N, Green E, Mkwetshana N, Clarke AM, et al. Helicobacter pylori prevalence in dyspeptic patients in the Eastern Cape Province of South Africa: ethnicity and disease status. S Afr Med J. 2010;100:734-7.

12. Brown LM. Helicobacter pylori: epidemiology and routes of transmission. Epidemiol Rev. 2000;22:283-97.

13. Gold BD, Moderator MD, Gilger MA, Discussant MD, Czinn SJ, Discussant MD. New diagnostic strategies for detection of Helicobacter pylori infection in pediatric patients. Gastroenterol Hepatol (NY). 2014;10(12 Suppl 7):1-19. 
14. Elwyn G, Taubert M, Davies S, Brown G, Allison M, Phillips C. Which test is best for Helicobacter pylori? A cost-effectiveness model using decision analysis. Br J Gen Pract. 2007;57:401-3.

15. Palmer DO, Watson KR, Allen MJ. Helicobacter pylori Infection and peptic ulcer disease in Cameroon, West Africa. J Clin Gastroenterol. 1994;18:162-4.

16. Ndip RN, Malange TAE, Ojongokpoko JEA, Luma HN, Malongue A, Akoachere JFTK, et al. Helicobacter pylori isolates recovered from gastric biopsies of patients with gastro-duodenal pathologies in Cameroon: current status of antibiogram. Trop Med Int Health. 2008;13:848-54.

17. Begue RE, Gonzales JL, Correa-Gracian H, Tang SC. Dietary risk factors associated with the transmission of Helicobacter pylori in Lima, Peru. Am J Trop Med Hyg. 1998;59:637-40.

18. Mohammad M, Josef T, Rumiko S, Yasutoshi K, Fumihiko K, Miyuki M, et al. Extremely low Helicobacter pylori prevalence in North Sulawesi, Indonesia and identification of a Maori-tribe type strain: a cross sectional study. Gut Pathog. 2014;6:42.

19. Hoang TT, Bengtsson C, Phung DC, Sorberg M, Granstrom M. Seroprevalence of Helicobacter pylori infection in urban and rural Vietnam. Clin Diagn Lab Immunol. 2005:12(1):81-5.

20. Yim JY, Kim N, Choi SH, Kim YS, Cho KR, Kim SS, et al. Seroprevalence of Helicobacter pylori in South Korea. Helicobacter. 2007;12:333-40.

21. Ndip RN, Malange AE, Akoachere JF, MacKay WG, Titanji VP, Weaver LT. Helicobacter pylori antigens in the faeces of asymptomatic children in the Buea and Limbe health districts of Cameroon: a pilot study. Trop Med Int Health. 2004;9:1036-40.
22. Malcolm CA, MacKay WG, Shepherd A, Weaver LT. Helicobacter pylori in children is strongly associated with poverty. Scott Med J. 2004;49:136-8.

23. Pilotto A, Franceschi M. Helicobacter pylori infection in older people. World J Gastroenterol. 2014;20(21):6364-73.

24. Sostres C, Gargallo CJ, Lanas A. Interaction between Helicobacter pylori infection, nonsteroidal anti-inflammatory drugs and/or lowdose aspirin use: old question new insights. World J Gastroenterol. 2014;20(28):9439-50.

25. Vinagre RM, Vilar-e-Silva A, Fecury AA, Martins LC. Role of Helicobacter pylori infection and lifestyle habits in the development of gastroduodenal diseases in a population from the Brazilian Amazon. Arq Gastroenterol. 2013;50(3):170-4.

26. Zhang L, Eslick GD, Xia HH, Wu C, Phung N, Talley NJ. Relationship between alcohol consumption and active Helicobacter pylori infection. Alcohol Alcohol. 2010;45:89-94.

27. Murray LJ, McCrum EE, Evans AE, Bamford KB. Epidemiology of Helicobacter Pylori infection among 4742 randomly selected subjects from northern Ireland. Int J Epidemiol. 1997;26:880-7.

28. Ogihara A, Kikuchi S, Hasegawa A, Kurosawa M, Miki K, Kaneko E, et al. Relationship between Helicobacter pylori infection and smoking and drinking habits. J Gastroenterol Hepatol. 2000;15:271-6.

29. Fletcher DR, Shulkes A, Hardy KJ. The effect of cigarette smoking on gastric acid secretion and gastric mucosa blood flow in man. Aust NZ J Med. 1985;15:417-20.
Ready to submit your research? Choose BMC and benefit from:

- fast, convenient online submission

- thorough peer review by experienced researchers in your field

- rapid publication on acceptance

- support for research data, including large and complex data types

- gold Open Access which fosters wider collaboration and increased citations

- maximum visibility for your research: over 100M website views per year

At BMC, research is always in progress.

Learn more biomedcentral.com/submissions 